\title{
As transformações na esfera pública e a ação ecológica: educação e política em tempos de crise da modernidade
}

\author{
Isabel Cristina de Moura Carvalho
}

Universidade Luterana do Brasil, Programa de Pós-Graduação em Educação

University California San Diego, Center for Iberian and Latin American Studies

\section{Introdução}

No horizonte de transformações da sociedade contemporânea estão produzindo-se novos contextos socioculturais que incidem sobre a experiência do sujeito moderno; a exigência, contudo, é a de dar sentido à sua existência, em tempos de crise do modelo societário. Um dos traços dessas mudanças na experiência societal contemporânea pode ser localizado no processo de privatização/subjetivação do espaço público. Nesse sentido, muito já se tem dito sobre as tendências de declínio da esfera pública (Sennett, 1989) e sobre a emergência de uma orientação narcísica predominando como padrão societário (Lasch, 1985). Poderíamos afirmar que reposicionar ego e socius, privado e público, ética e estética, tendo como pano de fundo a crise dos fundamentos do sujeito e das esferas de ação societais, é o drama do sujeito contemporâneo. Um drama que se expressa nos dilemas político-existenciais dos novos perfis de subjetividade e padrões de engajamento para a ação coletiva.

A modernidade em crise tem sido discutida por muitos autores e pode ser analisada por várias pers- pectivas, conforme seja pensada como ruptura mais ou menos radical com as condições de instauração do modelo societário moderno. Assim, sem desconsiderar as opções epistemológicas que subjazem às categorias de pós-modernidade e alta modernidade, preferimos pensar em termos de uma modernidade em crise, destacando-a como um tempo de transição societária, com a conseqüente potencialização dos riscos e das incertezas, gerando um solo de alta complexidade para a gestão da vida individual e coletiva.

De um modo geral, pode-se identificar nos questionamentos à autonomia da Razão, bem como nas suspeitas sobre a filosofia da consciência, a crise das categorias metafísicas, na qual se fundam o humanismo moderno e o sujeito que lhe corresponde: o sujeito da consciência, estável, centrado, senhor de si, legítimo portador de uma vontade assegurada por essa Razão. Ocorre, contudo, que em condições de crise essa Razão unificadora sofre um processo de esfacelamento. Essa fratura torna impossível restituir uma fundamentação transcendental para a ontologia, como bem o demonstrou Heidegger. Nesse sentido, as linhas que separam sujeito e objeto, universal e parti- 
cular, indivíduo e sociedade, subjetivo e objetivo, linguagem e experiência, discurso e referência, se tornam porosas e permeáveis, contribuindo para a deriva de um sujeito em posição de profundo desamparo ou ainda de desencaixe (Giddens, 1994) ante os seus próprios fundamentos.

A condição de desamparo e o mal-estar na modernidade podem ser tematizados a partir de vários aspectos da vida social. Elegemos pensá-los desde os novos agenciamentos entre esfera pública e subjetividade, resultando em formas de ação política ressignificadas no contexto contemporâneo. É nessa fronteira entre as esferas pública e privada, compreendida não como demarcação de campos antagônicos, mas como faixa de permanente negociação inter e intra-subjetiva, que reside a nossa questão. Contudo, entre as formas de subjetivação que podemos encontrar na sociedade contemporânea, vamos nos deter num sujeito que pode ser compreendido enquanto um tipo ideal, ambientalmente orientado, capaz de encarnar os dilemas societários, éticos e estéticos configurados pela crise societária em sua tradução contracultural, tributário de um projeto de sociedade socialmente emancipada e ambientalmente sustentável.

Esse sujeito é um locus emblemático das buscas contemporâneas de ressignificar os agenciamentos da experiência individual e coletiva. Traduz os tensionamentos éticos e políticos acerca de uma nova ordem societária, possibilitando as condições que produzem um sujeito e uma subjetividade ecológicos. É desde a legitimidade conquistada pela crítica ecológica contracultural à sociedade instituída que este sujeito ecologicamente orientado vai remeter a um modo instituinte de ser, posicionado à margem (alternativo) e animado pela pretensão libertária de deslocar as fronteiras entre militância e estilo de vida, intimidade e esfera pública, saberes da vida e prática educativa.

\section{A ação ecologica e a revolução da revolução}

O manifesto de lançamento do Partido Verde (PV) no Rio de Janeiro, em 1986, registra o fortaleci- mento da presença do ideário ecológico e de seus militantes na cena política brasileira. Este texto pode ser tomado, entre tantos outros registros discursivos daquele momento, como um emblema da transformação da cultura política sob os efeitos da nova política ecológica. Um trecho desse manifesto merece destaque:

Você, por exemplo, pode acordar amanhã com uma vontade irresistível de colar cartazes ou de ajudar na produção de uma festa ou de brigar pela preservação de uma área verde que você gosta, mas que querem destruir. Por que não? E se você acordar amanhã com vontade de militar suas reclamações? Isso não vai fazer você um soldado atrelado à causa e por esse motivo preso para sempre num beco sem saída. Se o cotidiano fosse levado mais a sério, a mistura seria mais harmoniosa. No momento em que essas reclamações forem inseridas no ritual "de todo dia" elas vão ser mais facilmente realizadas e com mais prazer: e os militantes vão ter mais noites livres para ir ao cinema. (Crispun, 1986, p. 79)

Essa convocação é porta-voz de uma guinada cultural em direção a novos estilos e formas de pensar a ação política, ${ }^{1}$ particularmente evidenciada no campo ambiental. Essa fala e seu contexto são ilustrativos das mudanças nos referenciais de militância, nos discursos políticos de esquerda e, afinal, nos questionamentos sobre o que se considera a própria esfera da política. A política como estilo de vida (Giddens, 1994; Roszack, 1972), também relacionada à virada cultural dos novos movimentos sociais transclassistas

1 Entendo aqui o conceito de ação política no sentido de Arendt (1989, p. 15), o qual “a ação, única atividade que se exerce diretamente entre os homens sem a mediação das coisas ou da matéria, corresponde à condição humana da pluralidade, ao fato de que homens e não o Homem, vivem na Terra e habitam o mundo. Todos os aspectos da condição humana têm alguma relação com a política; mas esta pluralidade é especificamente a condição - não apenas a conditio sine qua non, mas a conditio per quam de toda a vida política". 
e à nova esquerda, é uma transformação importante na cultura política, com forte expressão no mundo ambiental. Nesse sentido, os percursos de vida e as experiências políticas estão marcados por um movimento de dupla face: inserção num trânsito coletivo para fora da política entendida como tradicional, em busca da nova política, e a experiência pessoal e singular dessas mudanças.

Nesse contexto, a entrada da natureza ou meio ambiente no campo da política pode ser vista como uma ampliação da esfera pública, na medida em que os destinos da vida, enquanto Bios, conquistam um espaço crescente como objeto de discussão política na sociedade. Como propôs Serres (1991) numa de suas conhecidas formulações, haveria que introduzir a natureza no pacto civilizatório através de um "contrato natural". ${ }^{2}$ Contudo, se podemos falar de uma politização da natureza pelos movimentos sociais e pelas lutas ecológicas emancipatórias, também se pode observar a tênue fronteira que aponta para uma biologização da política, ou seja, a afirmação de uma suposta ordem natural - o Bios - sobre a polis.

A tensão entre ampliação e/ou redução da esfera pública evidencia a pergunta sobre as possibilidades emancipatórias ou desagregadoras de um fazer político orientado pelo ideário ecológico. Muitas vezes o apelo ecológico busca legitimar-se a partir dos riscos dos desequilíbrios ambientais, no entanto, a crise ecológica real não oferece em si mesma a direção de uma orientação política. A crise dos recursos naturais e a consciência dos riscos que afetam a vida das populações e do planeta podem tanto atuar como uma força

2 "Volta a natureza! Isto significa: ao contrato exclusivamente social juntar o estabelecimento de um contrato natural de simbiose e de reciprocidade onde a nossa relação com as coisas deixaria domínio e posse pela escuta admirativa, pela reciprocidade e pela contemplação. [...] Contrato de simbiose: o simbiota admite o direito do hospedeiro, enquanto o parasita - nosso estado atual - condena à morte aquele que pilha e que habita, sem tomar consciência de que no final condena-se a desaparecer" (Serres, 1991, p. 51). agregadora, contribuindo para a formação do que Habermas (1995) chamou de uma comunidade de riscos compartilhados; quanto reforçar os mesmos mecanismos de desintegração social e ambiental que tendem a acelerar a apropriação dos bens ambientais pelos interesses privados, degradando não apenas a base de sustentação material do planeta, mas também as bases dos vínculos de solidariedade social.

Outro aspecto que tem sido objeto dos críticos da política ecológica e do movimento alternativo (Dupuy, 1980; Alphandéry, Bitoun \& Dupont, 1992; Huber, 1985) diz respeito aos paradoxos da autonomia, que atravessam as propostas ecológicas para a sociedade. A crítica mais dura à radicalização da autonomia no projeto emancipatório é desfechada por Ferry (1994), que vê na trajetória de uma esquerda libertária e democrática, egressa de maio de 1968, e na sua ética da autenticidade, ${ }^{3}$ o protótipo do ecologista reformista. $\mathrm{O}$ autor chega a perguntar-se se é possível pensar a ecologia como uma força política per si. Sua preocupação recoloca o paradoxo da radicalização da autonomia como emancipação individual e a dificuldade da ação política no campo ambiental. Para ele, a mentalidade autonomista dos anos de 1960, com sua ética da autenticidade, teria transformado o tu deves de uma ética que previa o controle das inclinações egoístas em favor do bem comum, num convite do tipo: seja você mesmo, "que pretende favorecer a auto-realização através da idéia de que a lei, longe de se nos impor do exterior, é imanente em cada indivíduo particular" (Ferry, 1994, p. 186).

Seja como partido, movimento, ou prática educativa, a presença do ecologismo e dos seus tensionamentos na ampliação-redução da esfera pública caracteriza os dilemas de uma nova cultura política, nos quais o projeto emancipatório passa a incorporar as lutas identitárias e a preocupação com a natureza, identificada por Giddens (1994) como política da

3 Definida como "viver de outro modo, viver a la carte, fazer cada uma suas próprias escolhas, viver sua vida" (Ferry, 1994, p. 187). 
vida. ${ }^{4}$ Nesse marco, destaca-se a articulação dos movimentos ecológicos a um conjunto de outros movimentos sociais de corte cultural e transclassistas. Por seu caráter inovador em termos de tipo de reivindicação, perfil de classe dos militantes e performances de ação, esses movimentos foram denominados pelos analistas políticos de "novos movimentos sociais" (Evers, 1984; Durham, 1984; Sherer-Warren, 1987; Cardoso, 1984).

No conjunto desses novos movimentos sociais, a temática ambiental, ao lado das questões de gênero, parece ter sido uma das que mais conseguiu penetrar na diversidade das lutas sociais nas últimas décadas e alcançar certa legitimidade em diferentes segmentos sociais, inclusive no âmbito das lutas populares e sindicais, que, de certa forma, foram, em um determinado momento, o contraponto desses novos movimentos. Os chamados movimentos sociais tradicionais, como os populares e os sindicais, vão constituir-se, por sua vez, como horizonte histórico que configura as condições de recepção e, conseqüentemente, alcance e legitimação dos novos movimentos. Nesse sentido, a cultura revolucionária dos anos de 1960 e de 1970 será a referência forte ante o qual as novas temáticas, como a ambiental, vão afirmar-se nos anos de 1980 e de 1990, ora como contraponto, ora como elemento a ser internalizado pelas lutas tradicionais. ${ }^{5}$

4 “A política da vida não é uma política de oportunidades vitais, mas de estilo de vida. Ocupa-se das disputas e das lutas sobre como devemos viver (como indivíduos e como humanidade) num mundo que era determinado pela tradição e pela natureza e está agora submetido às decisões humanas" (Giddens, 1994, p. 24).

5 Tornaram-se célebres as frases como "a luta ecológica não está nem à direita nem à esquerda, mas à frente" (Gabeira, 1986); "O Partido Verde não se define ideologicamente nem à esquerda nem à direita. Ainda bem!" (Berna, 1986). Frases como essas foram inúmeras vezes repetidas por lideranças ecologistas, tanto no Brasil como na Europa, que situavam a ação ecologista fora dos marcos do que era visto por esses atores como a velha política.

\section{Autonomia e emancipação: desafios éticos e políticos}

Reposicionar ego e socius, privado e público, ética e estética, tendo como pano de fundo a autonomização do sujeito e das esferas de ação societais, é o drama da nova esquerda contracultural, mas vai bem além desta.

Essa problemática repõe um dilema cujas raízes mais profundas podem ser encontradas na radicalização das tendências conflitivas que constituem a modernidade: emancipação e controle (Giddens, 1991); racionalização e subjetivação (Touraine, 1994); razão universal e individualismo (Harvey, 1993); subjetividade, cidadania/regulação e emancipação (Santos, 1995).

Dessa maneira, de acordo com a concepção de política da qual partem - e da aposta mais ou menos otimista no projeto emancipatório moderno -, diversas análises vão destacar na condição contemporânea os sinais de dissolução, declínio e mesmo morte da política; ou ainda, os sinais vitais da emergência de uma nova política.

No extenso debate sobre as vicissitudes da política na modernidade, seria possível, de maneira geral, identificar pelo menos três ênfases predominantes: os que destacam o aspecto de decadência da política na situação contemporânea; os que concordam com o diagnóstico de crise da política, mas que argumentam sobre possíveis saídas através da renegociação das relações público-privado; e os que preferem ressaltar os aspectos promissores dos novos espaços emancipatórios nas mudanças da cultura política contemporânea.

No primeiro grupo podem-se situar autores como Arendt (1989), Sennett (1989) e Hobsbawm (1995), que detectam na sobreposição da esfera privada sobre a pública, do indivíduo sobre o coletivo, ou, como nomeou Hobsbawm, do eu sobre o nós, um sinal de crise da política, da esfera pública e uma ameaça aos laços societários. Arendt discute a condição humana na modernidade, tomando-a, em contraposição ao paradigma greco-romano, como estan- 
do marcada pela alienação do mundo. A autora reflete sobre a diluição das fronteiras entre os domínios do público e do privado, indicando o declínio da esfera pública - o lugar do político e da ação humana por excelência. Vê na modernidade a emergência de uma nova esfera social que representa a ascensão dos interesses privados ao domínio público. A reflexão de Sennett, no mesmo sentido da análise de Arendt, aponta para uma compreensão do esvaziamento da esfera pública associado à crise da modernidade. Para o autor, os "sinais gritantes de uma vida pessoal desmedida e de uma vida pública esvaziada são resultantes de uma mudança que começou com a queda do Antigo Regime e com a formação de uma nova cultura urbana, secular e capitalista" (1989, p. 30). Sennett chama a atenção para a singularidade da experiência moderna de privacidade, da qual decorre uma tendência de psicologização dos problemas relativos ao campo do público, discutindo o problema do retraimento social como contraface aos processos emergentes de psicologização dos assuntos públicos. $\mathrm{O}$ autor entende as obsessões atuais para com a individualidade e a intimidade como tentativas de resolver, pela negação, o problema do público, já colocado desde o século XIX, que, segundo seu ponto de vista, ainda não terminou. Hobsbawm, em sua análise sobre o século XX, detecta nas mudanças sociais e culturais das últimas décadas um deslocamento no campo da política do "domínio do 'nós' para o 'eu”' (1995, p. 300). Mostra que até os anos de 1960 houve uma prevalência na percepção dos trabalhadores de que não poderiam melhorar a sua sorte pela ação individual, mas através de organizações definidoras de sua identidade de classe como os partidos e movimentos operários. Com os vários processos de privatização da vida impulsionados pela "tecnologia do dinheiro e da lógica do mercado", o autor indica o fortalecimento de uma cultura individualista e fala de uma "revolução cultural de fins do século XX que pode ser entendida como o triunfo do indivíduo sobre a sociedade, ou melhor, rompimento dos fios que antes ligavam os seres humanos em texturas sociais" (idem, p. 328).
Na segunda posição, predominam reflexões como as de Habermas (1984), que apontam para uma necessária rearticulação, ou as de Bauman (2000), que apontam para uma tradução das relações privadopúblico como caminhos para a política e o projeto emancipatório moderno. Nesse sentido, Habermas incorpora a crítica fundamental de Arendt à sociedade moderna e aos processos de despolitização e privatização da esfera pública como ameaças às condições de exercício legítimo do poder. No entanto, amplia o conceito aristotélico-arendtiano de política, que, tomando como base a polis grega, restringe a esfera pública aos cidadãos que efetivamente têm interesse em temas públicos. Habermas, embora reconheça a decadência da esfera pública burguesa, reafirma o projeto moderno como inacabado e potencialmente libertário. $\mathrm{O}$ imbricamento entre o privado e o público indica a complexidade da sociedade moderna, cujo desafio é respeitar a relativa autonomia de cada uma dessas esferas, impedindo que uma seja reduzida ou subordinada à outra. ${ }^{6} \mathrm{Em}$ Bauman também encontramos o argumento de uma desconstrução da política, tendo em vista as dificuldades de tradução entre a esfera privada e a pública e as conseqüências de sua autonomização e privatização. Para o autor, o público recuou para buscar abrigo em lugares politicamente inacessíveis, e o privado está a ponto de retirar-se para a própria auto-imagem. Contudo, como Habermas, Bauman também aponta para um caminho de superação da crise: "Para adaptar a Agora aos indivíduos livres e à sociedade livre é preciso interromper ao mesmo tempo sua privatização e despolitização. É preciso restabelecer a tradução do privado para o público" (2000, p. 113).

\footnotetext{
6 Para Habermas, que analisa a constituição da esfera pú-
} blica burguesa e suas mudanças estruturais à luz das condições do Estado moderno, os domínios do público e do privado interpenetram-se. Isso marca a estrutura básica da esfera pública burguesa do século XVIII, "entendida como a esfera das pessoas privadas reunidas em um público" (1984, p. 42). 
Em contrapartida, autores como o próprio Roszack (1972), Giddens (1991, 1993, 1994) e Santos $(1995,2000)$ tendem a enfatizar na situação presente a oportunidade de uma recomposição das esferas do público e do privado e a abertura de novos espaços de negociação entre a vida individual e coletiva, e, assim, de novas maneiras de fazer política e existir como sujeito político. Roszack, que fala como um analista-militante, deixa claro que simpatiza com as tentativas de inovar, ainda que sob o risco de diluição da política. Para ele, uma política que "não parece absolutamente política" tem a vantagem de ser "inexpugnável às defesas psíquicas e sociais convencionais" (1972, p. 158)

Partindo de uma visão dialética, Giddens (1991) aponta para as interações de mão dupla entre uma dimensão pessoal e uma dimensão que ele nomeia de sistemas abstratos. ${ }^{7}$ Desse modo, assume uma perspectiva mais otimista das possibilidades de resposta no plano da vida privada em condições de alta modernidade. Para o autor:

Uma preocupação com a auto-satisfação não é apenas uma defesa narcisista contra um mundo externo ameaçador, sobre o qual os indivíduos têm pouco controle, mas também em parte uma apropriação positiva de circunstâncias nas quais as influências globalizadas invadem a vida cotidiana. (p. 126)

Giddens, portanto, percebe a vida privada não como uma dimensão residual das mudanças nos sistemas abstratos, mas como uma esfera ativa que comporta reações, de forma que as mudanças que aí ocorrem também afetam as instituições globalizadas da

7 Uma das premissas básicas do autor para a compreensão da modernidade é que esta comporta um ambiente de alto risco pela dificuldade de controlar a complexidade dos fenômenos que instaura. Na base dos processos de racionalização da modernidade estão mecanismos de abstração que, para serem eficazes, envolvem laços de confiança em instituições que operam nesse ambiente de alto risco (Giddens, 1991). modernidade. Para Santos (1995), que se autodenomina um utopista, "vivemos um período de transição paradigmática, tanto no plano epistemológico - da ciência moderna para um conhecimento pós-moderno - como no plano societal - da sociedade capitalista para uma forma societal que tanto pode ser melhor como pior" (p. 283). Nessa nova forma societal, que ele caracteriza como pós-moderna, a reafirmação da subjetividade no domínio da política poderia ser vista como uma resposta emancipatória à subjetividade coletiva imposta pela modernidade - tanto no capitalismo quanto no socialismo - que subsumiu em si as subjetividades individuais. Ao contrário de Hobsbawm, que vê o deslocamento do "nós para o eu" como um legado do fracasso do projeto moderno sobre o qual não se pode construir o futuro, Santos considera os deslocamentos em direção ao eu como parte da emergência de uma subjetividade da transição paradigmática "para quem o futuro é uma questão pessoal” (2000, p. 346).

A luta paradigmática aqui é levada a cabo por sujeitos interpelados pessoalmente e engajados coletivamente num projeto utópico emancipatório, que o autor chama de viajantes paradigmáticos, cuja condição instável e dilemática é formulada na metáfora da navegação de cabotagem. ${ }^{8}$

Como na navegação de cabotagem, o projeto emancipatório e autonomista moderno arrisca-se entre as margens do continente e do mar alto, do perigo e da oportunidade; ou, ainda, da transcendência no mundo e da transcendência $d o$ mundo.

8 A cabotagem foi a forma de navegação dominante desde tempos imemoriais até a expansão européia do século XV, e é usada ainda hoje. Implica navegar fora dos limites, mas em contato físico com eles, e ir realizando outras atividades ao longo do trajeto, como a pesca ou o comércio. Quanto mais longe se estiver e menores, porque vistos de longe, forem os limites, maiores serão as possibilidades de autonomia. Mas, um passo a mais, que faça perder de vista esses limites, pode transformar uma autonomia estimulante num caos destrutivo (Santos, 2000, p. 354). 


\section{Emancipação, autonomia e ecologismo: o ambiente dilemático de uma ação político-pedagógica}

O conjunto das práticas educativas emancipatórias, de um modo geral, mas particularmente as ambientais, estão atravessadas pelos paradoxos da autonomia. Autonomia aqui entendida em duas acepções: num primeiro plano, como núcleo forte do ideário contracultural e ecológico que busca a transcendência como libertação da ordem; e, num horizonte mais amplo, como processo de desreferencialização que tem seu ponto de partida desde um tempo das novas políticas, no clima de transcendência e rupturas dos anos de 1960, mas que arrisca aportar, errante, num tempo da não-política, porto anti-utópico da transcendência do mundo.

A questão anteriormente identificada como "paradoxos da autonomia" repõe, no âmbito da educação, a tensão entre uma ação pedagógica que busca ampliar os espaços de autonomia no mundo, ou, no limite, ações investidas de um desejo de autonomia do mundo. Essa questão mantém a pergunta sobre qual poderia ser a contribuição da ação ambiental para a esfera pública e como esta se comporta, ora ampliando o campo de cidadania e dos direitos, ora restringindo-o com o que parecia uma excessiva subjetivação e individualização das questões e formas de ação? Pode-se reencontrar nos sentidos acionados pela experiência educativa ambientalmente orientada as predisposições e atitudes políticas do ideário ecológico, como a vontade contestatória de fundo romântico, o inconformismo da contracultura, a militância como habitus, a constituição de um sentimento de crítica radical, o elogio da margem e do alternativo como lugar de recusa do estabelecido e reinvenção da existência pessoal e política.

$\mathrm{Na}$ experiência pedagógica de uma educação ambiental, esses traços podem ser reencontrados na crítica à racionalidade instrumental e disciplinar, na reivindicação de uma revolução epistemológica, na pretendida guinada do pensamento e das formas de pensar, bem como nas dificuldades daí decorrentes em penetrar no coração do campo educativo e nos métodos e práticas educacionais tradicionais. Assim, reeditase na esfera educativa as antinomias do projeto emancipatório autonomista que constitui o núcleo político, existencial e epistêmico do campo ambiental.

A idéia de mudanças radicais abarca não apenas uma nova sociedade, mas também um novo sujeito da educação, que se vê como parte dessa mudança societária e a compreende como uma revolução de corpo e alma, ou seja, uma reconstrução do mundo, incluindo o mundo interno e os estilos de vida pessoal. Esse parece ser o elemento diacrítico que confere o caráter promissor e sedutor do campo ambiental e do saber que ele busca fomentar em suas esferas de formação de especialistas, publicações e teorização. Como já anunciada por Dupuy (1980), a máxima ecológica que clama por mudar todas as coisas, evoca uma transformação não apenas política mas da política, isto é, muda-se também a maneira de compreender, viver e fazer política, acenando com novos trânsitos, oportunidades e riscos para a ação na esfera política e nas práticas educativas.

\section{Referências bibliográficas}

ALPHANDÉRY, Pierre; BITOUN, Pierre; DUPONT, Yves. O equivoco ecológico: riscos políticos. São Paulo: Brasiliense, 1992.

ARENDT, Hanna. A condição humana. Rio de Janeiro: Forense, 1989. BAUMAN, Zigmund. Em busca da política. Rio de Janeiro: Jorge Zahar Editor, 2000.

BERNA, Vilmar. Desafios que precisamos enfrentar. In: GABEIRA, Fernando (Org.). Partido Verde: propostas de ecologia política. Rio de Janeiro: Ánima, 1986. p. 27-32 (Coleção Ánima Verde).

CARDOSO, Ruth. Movimentos sociais e urbanos: balanço crítico. In: ALMEIDA, Maria Hermínia Tavares de; SORJ, Bernardo (Orgs.). Sociedade política no Brasil pós-64. São Paulo: Brasiliense, 1984. p. 215-239.

CRISPUN, Denise. Nós, os tigres de papel. In: GABEIRA, Fernando (Org.). Partido Verde: propostas de ecologia política. Rio de Janeiro: Ánima, 1986. p. 79-82.

DUPUY, Jean Paul. Introdução à crítica da ecologia política. Rio de Janeiro: Civilização Brasileira, 1980. 
DURHAM, Eunice R. Movimentos sociais e a construção da cidadania. Novos Estudos, São Paulo: CEBRAP, v. 10, p. 24-31, out. 1984.

EVERS, Tilman. A face oculta dos novos movimentos sociais. Novos Estudos, São Paulo: CEBRAP, v. 2, abr. 1984.

FERRY, Luc. A nova ordem ecológica: a árvore, o animal e o homem. São Paulo: Ensaio, 1994.

GABEIRA, Fernando (Org.). Partido Verde: propostas de ecologia política. Rio de Janeiro: Ánima, 1986 (Coleção Ánima Verde). GIDDENS, Anthony. As conseqüências da modernidade. São Paulo: UNESP, 1991.

. Más allá de la izquierda y la derecha: el futuro de las políticas radicales. Madrid: Cátedra, 1994.

. A transformação da intimidade: sexualidade, amor e erotismo nas sociedades modernas. São Paulo: UNESP, 1993.

HABERMAS, Jürgen. O Estado-nação europeu frente aos desafios da globalização. Novos Estudos, São Paulo: CEBRAP, n. 43, p. 87-101, 1995.

. Mudança estrutural da esfera pública: investigações quanto a uma categoria da sociedade burguesa. Rio de Janeiro: Tempo Brasileiro, 1984 (Biblioteca Tempo Universitário, 76).

HARVEY, David. A condição pós-moderna. São Paulo: Loyola, 1993.

HOBSBAWM, Eric. A era dos extremos: o breve século XX: 19141991. São Paulo: Companhia das Letras, 1995.

HUBER, Joseph. Quem deve mudar todas as coisas: as alternativas do movimento alternativo. Rio de Janeiro: Paz e Terra, 1985. LASCH, Christopher. The minimal self. London: Picador, 1985. ROSZACK, Theodore. A contracultura. Petrópolis: Vozes, 1972. SANTOS, Boaventura de Souza. Pela mão de Alice: o social e o político na pós-modernidade. São Paulo: Cortez, 1995.
- A crítica da razão indolente: contra o desperdício da experiência. São Paulo: Cortez, 2000.

SENNETT, Richard. O declínio do homem público: as tiranias da intimidade. São Paulo: Companhia das Letras, 1989.

SERRES, Michael. O contrato natural. Rio de Janeiro: Nova Fronteira, 1991.

SHERER-WARREN, Ilse. Os novos movimentos sociais na América Latina. São Paulo: Brasiliense, 1987.

TOURAINE, Alain. Crítica da modernidade. Petrópolis: Vozes, 1994.

ISABEL CRISTINA DE MOURA CARVALHO, doutora em educação pela Universidade Federal do Rio Grande do Sul (UFRGS), é professora licenciada da Universidade Luterana do Brasil (Canoas, RS), atuando em educação, psicologia social e estudos ambientais. Atualmente está em estágio de pós-doutorado na University California San Diego (UCSD)/Center for Iberian and Latin American Studies (CILAS), com bolsa da Coordenação de Aperfeiçoamento do Pessoal de Ensino Superior (CAPES), para 2006-2007. Últimas publicações: Discutindo a educação ambiental a partir do diagnóstico em quatro ecossistemas no Brasil (Educação e Pesquisa, v. 31, n. 2, p. 301-313, maio/ago. 2005); Educação ambiental: a formação do sujeito ecológico (São Paulo: Cortez, 2004, coleção Docência em Formação); A invenção do sujeito ecológico: sentidos e trajetórias da educação ambiental no Brasil (Porto Alegre: Editora da UFRGS, 2. ed, 2002); Pesquisa atual: “As perspectivas da educação ambiental e a formação do sujeito ecológico: o mal estar da cultura e a crise socioambiental". E-mail: icmcarvalho@uol.com.br

Recebido em novembro de 2004 Aprovado em abril de 2005 
dáticos e quais novos sentidos e significados são produzidos. Identificamos no discurso sobre a formação para o trabalho sentidos e significados que precisam ser refletidos pela comunidade educacional, considerando as relações estabelecidas entre os contextos econômico e educacional que resultam em formas de ensino e aprendizagem que acentuam o caráter de performatividade (Lyotard).

Palavras-chave: ensino médio; livro didático; políticas curriculares; trabalho

Discourse on the world of work in secondary school textbooks

In this study, we focus on discourse on the world of work in science textbooks of the collection With an eye on the world of work (De olho no mundo do trabalho), published by Scipione, as part of a curriculum policy for secondary education. We understand that the construction of curriculum policies is a complex process of negotiation that includes influence, production and dissemination of texts which circulate and which are subject to continuous recreation in the context of practice. We analyse how discourse on the world of work is appropriated and re-contextualised in the elaboration of school textbooks and what new meanings are produced. In the discourse on training for work, we identify meanings that the educational community needs to reflect upon, considering the relations established between educational and economic contexts that result in forms of teaching and learning, accentuating the character of performance.

Key-words: secondary education; textbook; curriculum policies; work and education

Discursos del mundo del trabajo en los libros didácticos de la enseñanza secundaria

En este estudio, enfocamos los discursos sobre el mundo del trabajo en los libros didácticos de la área de ciencias de la colección De ojo en el mundo del trabajo (editora Scipione), como parte de una política curricular para la enseñanza secundaria. Entendemos la constitución de políticas curriculares como un proceso de negociación complejo que incluye influencia, producción y diseminación de textos circulantes, que están sujetos a la recreación continua en el contexto de la práctica (Ball). Analisamos como los discursos sobre el mundo del trabajo son apropiados y contextualizados (Bernstein) en la elaboración de libros didácticos y en los cuales los nuevos sentidos y significados son producidos. Identificamos en el discurso sobre la formación para el trabajo, sentidos y significados, que precisan ser pensados por la comunidad educacional, considerando las relaciones establecidas entre los contextos económico y educacional que resultan en formas de enseñanza y aprendizaje que acentuan el caracter de performatividad (Lyotard).

Palabras claves: enseñanza secundaria; libro didáctico; políticas curriculares; trabajo

Isabel Cristina de Moura Carvalho

As transformações na esfera pública e a ação ecológica: educação e política em tempos de crise da modernidade

Discute as transformações da esfera pública contemporânea e a emergência de novos modos de ação política associados à formação de um campo político e pedagógico ambiental. Afirma que a ação política ambiental, no contexto do ambientalismo e da nova esquerda contracultural, pode ser considerada uma das expressões da crise da modernidade. Nesse sentido, os movimentos ecológicos buscam reposicionar o ego e o socius, o privado e o público, a ética e a estética na esfera de ação societal. Isso repõe um dilema que remete tanto às tendências conflitivas da modernidade quanto ao seu projeto emancipatório. Ante essa problemática, algumas análises destacam a dissolução e o declínio da política, enquanto outras enfatizam a emergência de uma nova forma de ação política. Por fim, o artigo explora os rebatimentos dessas mudanças sociais no campo da ação educativa, particularmente a educação ambiental, preocupada com a construção de um sujeito ecológico.

Palavras-chave: ação política; modernidade; educação ambiental; sujeito ecológico

Changes in the public sphere and ecological action: education and politics in the crisis of modernity The article discusses transformations in the contemporary public sphere and the emergence of new types of political action, which are related to the creation of a political and pedagogical environmental field. The political environmental action may be considered as part of the counterculture and the new left movements. Therefore, it may be taken as one of the expressions of the crisis of modernity, which is redefining the role of social action in terms of individual, private, public, ethical and aesthetic action. This dilemma exposes the conflicts which constitute modernity and its emancipating project. In the face of this problematic, some analyses emphasise the dissolution and the decline of politics whilst others underline the emergence of a new way of doing politics. Finally, the article explores the aftermaths of these social changes in the educational field, especially in environmental education, which is concerned with the construction of an ecological self. Key-words: political action; modernity; environmental education; ecological self 
Las transformaciones en la esfera pública y acción ecológica: educación y política en tiempos de crisis de la modernidad

Discute las transformaciones de la esfera pública contemporanea y la emergencia de nuevos modos de acción política asociados a la formación de un campo político y pedagógico ambiental. Afirma que la acción politica ambiental, en el contexto del ambientalismo y de la nueva izquierda contracultural. puede ser considerada una de las expresiones de la crisis de la modernidad. En este sentido, los movimientos ecológicos buscan reposicionar el ego y el socius, el privado y el público, la ética y la estética en la esfera de acción social. Esto repone un dilema que remite tanto a las tendencias conflictivas de la modernidad cuanto a su proyecto emancipatorio. Frente a esa problemática, algunos análisis destacan la disolución y el declinio de la política, en cuanto otros enfatizan la emergencia de una nueva forma de acción politica. Por fin, el artículo explora los rebatimientos de esos cambios sociales en el campo de la acción educativa, particularmente la educación ambiental, preocupada con la construcción de un sujeto ecológico. Palabras claves: acción politic; modernidad; educación ambienta; sujeto ecológico

\section{Ana Maria R. Gomes}

O processo de escolarização entre os Xakriabá: explorando alternativas de análise na antropologia da educação

A criação das escolas estaduais indígenas, pelo Programa de Implantação das Escolas Indígenas de Minas Gerais (PIEI-MG), em 1997, foi um fato marcante para todos os povos envolvidos. Entre os Xakriabá, o processo de escolarização teve seu início pelo menos vinte anos antes, e foi intensificado de modo muito acelerado com o início do funcionamento das escolas estaduais indígenas. Tal expansão acelerada gerou um contexto escolar com características muito peculiares. No artigo busca-se explorar algumas perspectivas de análise sobre os processos de escolarização, propostas pela antropologia da educação. A presença dos "encostados" ou a possibilidade de "reprovação dos melhores", dois exemplos de aspectos que caracterizam as escolas xakriabás, alertam-nos para a necessidade de se passar a perceber também como elementos culturais os aspectos da vida cotidiana (como as modalidades de interação verbais e não-verbais e as relações de autoridade) que não alcançam imediata visibilidade, e não são, portanto, considerados parte da especificidade cultural que marca a escola xakriabá.

Palavras-chave: educação indígena; cultura escolar; antropologia da educação

The process of schooling among the Xakriabá people: an exploration of alternative forms of analysis in the anthropology of education

The creation of indigenous public schools in 1997 by means of the Programme for the Implantation of Indigenous Schools in the State of Minas Gerais (PIEI-MG) was an important event for all the indigenous groups involved. Among the Xakriabá people, the process of schooling began twenty years earlier, and was intensified by the creation of the indigenous public schools. This accelerated expansion generated a very specific school context. In this article, explore the different perspectives of analysis of the schooling process proposed by the anthropology of education. Two examples of the characteristics of the xakriabá schools - the attendance of non official students, the "indolent", and the possibility of failing the best students - focus our attention on those aspects of daily life that are not generally perceived as cultural elements (such as the verbal and non verbal interactional styles and the relations of authority). These aspects are not immediately visible and are not, therefore, taken as constitutive of the cultural specificity of the xakriabá school.

Key-words: indigenous education; school culture; anthropology of education

El proceso de escolaridad entre los Xakriabás: explorando alternativas de análisis en la antropología de la educación

La creación de las escuelas estatales indigenas, através del Programa de Implantación de las Escuelas Indígenas de Minas Gerais (PIEI-MG) en 1997, fue un hecho marcante para todos los pueblos envueltos. Entre los Xakriabás, el proceso de escolaridad tuvo su inicio por lo menos veinte años antes, y fue intensificado de un modo muy acelerado, con el inicio del funcionamiento de las escuelas estatales indígenas. La expansión acelerada produjo un contexto escolar con características muy peculiares. En el articulo explorar algunas perspectivas de análisis al respecto de los procesos de escolaridad, propuestas por la antropología de la educación. La presencia de los "arrimados" o la posibilidad de "reprobación de los mejores", son dos aspectos que caracterizan a la escuela xakriabá, poniéndonos sobre aviso para la necesidad de pasar a notar, también, como elementos culturales, los aspectos de la vida cotidiana (como las modalidades de interacción verbal y noverbal y las relaciones de autoridad) que no alcanzan una inmediata visibilidad, y no son, por lo tanto, considerados como parte de la 